\title{
A Critical Examination of the Arab Undergraduate Students' Perceptions of their Academic Arabic Proficiency in Three EMI Universities in the UAE
}

\author{
Taghreed Ibrahim Masri ${ }^{1}$ \\ ${ }^{1}$ Faculty of Communication, Arts and Sciences, Canadian University Dubai, Dubai, United Arab Emirates \\ Correspondence: Taghreed Ibrahim Masri, Faculty of Communication, Arts and Sciences, Canadian University \\ Dubai, Dubai, UAE.
}

Received: January 27, 2019

Accepted: March 4, 2019 Online Published: March 7, 2019

doi: $10.5539 /$ elt.v12n4p21

URL: https://doi.org/10.5539/elt.v12n4p21

\begin{abstract}
The overwhelming power that English enjoys has become a threat to many indigenous languages that are losing the battle against English dominance and hegemony. One facet for this threat is the use of English as a medium of instruction (EMI). The EMI policy has been a naturalized and taken-for-granted practice without questioning or problematizing. As a result, academic Arabic is almost absent from the academic scene in the UAE higher education. This study aims to problematize the use of English as medium of instruction at three universities in the United Arab Emirates. It also aims to critically explore the perceptions of Arab university students who were in Arabic schools, of their Arabic proficiency after studying at university. Based on critical theoretical framework and approached from interpretive and critical paradigms, the study used a mixed-methods approach of quantitative and qualitative data collection methods. 268 surveys and 20 semi-structured interviews showed that students were aware of the decline in their Arabic proficiency due to studying via English. Results also indicated that students showed symptoms of Academic language attrition.
\end{abstract}

Keywords: proficiency, EMI, Arabic language, hegemony, problematization, inequity, marginalization

\section{Introduction}

\subsection{The Problem Statement}

English has gone beyond being taught as a foreign/second language to be the medium of instruction in many European, Asian and African countries. It is now considered an essential lever for success in many globalizing economies and is viewed as the mantle of 'language of power' (Marsh, 2006, p. 30). It has been taken for granted that "knowing English is like possessing the fabled Aladdin's lamp, which permits one to open, as it were, the linguistic gates" to different spheres and that it provides linguistic power (Kachru, as cited in McKay, 2010, p. 96). This overwhelming power that English enjoys, has become a threat to many indigenous languages that are losing the battle against English dominance and hegemony. One facet for this threat is the use of English as a medium of instruction (EMI). The worldwide shift from English being taught as a foreign language (EFL) to English being the medium of instruction (EMI) for academic subjects, according to a recent report published by the British Council and Oxford university, is happening at a very fast pace, with English being increasingly used as the lingua franca in different educational institutions, from primary schools to university level (Chapple, 2015).

Moreover, this anglicizing of universities is occurring without a thorough evaluation of how this policy ends up with diglossia dividing the functions between languages where English is perceived as the academic 'high' language (Airey, 2009), while Arabic is playing a very minor role not only in academic context but also in society in general due to the dominance of English also outside the gates of universities. However, the use of English as MI is a real threat to Arabic since "in diglossic societies, the formal and prestigious functions are the first to be lost; hence the importance of higher education" (Coleman, 2006, p. 2). There is a possibility that Gulf countries run the risk of having a new generation graduating from these institutions without being "connected in any kind of organic way to society as a whole; a generation of people who cannot even speak to their parents" (Ahmed, 2011, p. 125). This might be a natural consequence of the state of disconnect from Arabic during all the years of studying at university. We need to ask: How will students learn to see their own culture in a positive 
light "if Anglo- American norms dominate a newly homogenized ... academic discourse? [And] if the only language on the PowerPoint slides is English" (Coleman, 2006, p. 10).

\subsection{Importance of the Problem}

EMI needs to be problematized. The decision to use a particular language as a medium of instruction is a very crucial decision because it decides on which language is given prestige, power, resources, and which language is relegated to a secondary position in society (Tsui, \& Tollefson, 2004), which is here Arabic. These policies, which are not purely guided by educational agenda but by social, political, and economic agendas, should be questioned (Ibid). Hanafi and Arvanitis (2014) remind us that "language of instruction is the product of both policy and history" (p. 6) and is a very serious issue in that the conflict over languages reflects social conflicts, and the wars of languages imply and signal an underlying educational or economic war (Calvet, as cited in Hanafi \& Arvanitis, 2014). Ahmed (2011) argues that today's globalized system of education may be aiding in either erasing weak cultures or blurring and overshadowing stronger ones as a result of the imported education and rampant spread of emphasis on English, which "is beginning to sideline Arabic resulting in the linguistic and cultural loss of those who identify with it" (p. 120).

The study aims to spot light on EMI's impact on students' proficiency in Arabic. Rogier (2012) argues, "Once language is learned the proficiency level may actually decrease if there are not maintenance strategies in place" (p. 31). So, if the target of EMI is to improve the students' English proficiency, it might lead to first language attrition and students might lose their literacy skills in MSA as a result. When students leave high school, their proficiency in Arabic may have not reached a stable level. It may need to be developed especially if we take into consideration that Modern Standard Arabic (MSA) is not used for daily communication. It is the language of literacy. Therefore, if students do not continue learning it, there is a possibility that they will lose it. L1 attrition is seen as "a by-product of a speaker's contact with a second language where input and use of L1 diminishes to a critical point" (Sebina, 2014, p. 55). Thus, students are denied their right to receive education in their mother tongue and are also "divested of their right to identify with, to maintain and to fully develop their mother tongue in the name of globalization" (Cho, 2012, p. 23).

\subsection{Literature Review}

\subsubsection{Neoliberalism, Globalization and Higher Education}

Neoliberal ideologies have penetrated contexts of learning language in ways that consolidate powerful languages in their dominant positions. Because of these ideologies, the innocent delight of learning has been commodified, and turned from being an intrinsic good into a saleable one (Grant, 2009, p. xii). The most prominent example is "English, which has become synonymous with economic growth and prosperity" because many countries perceive it as their access to prosperity and economic mobility and prosperity, as the free market mindset promises (Ennser-Kananen, Escobar, \& Bigelow, 2017, p. 17). However, it cannot be denied that the fast-growing role that English plays internationally is both a product of neoliberalism and a promoter for it because it is associated with social, linguistic, political, intellectual, cultural, and economic advantages (Hu, \& Barnawi, 2015, p. 454). In conclusion, modernization should not be taken as the reason for "the wholesale adoption of a Western curriculum and use of English as a medium of instruction in higher education" for science, math and technology (Badry, 2012, p. 95).

\subsubsection{Language-in- Education Policy}

Language education policy (LEP) refers to "a mechanism used to create de facto language practices in educational institutions" through imposing and manipulating language policy by those in authority who have the power to turn ideology into practice through formal education (Shohamy, 2003). Through LEP, authorities carry out LP decisions in the contexts of schools and universities and decide on the use of home languages, foreign and second languages (Shohamy, 2003). Language planning is a deliberate attempt that aims to affect the linguistic situation and to influence or modify the linguistic market (Bull, 2013). Schiffman differentiates between overt and covert language policies. He suggests that overt LPs are explicit, formalized, and manifest while the covert LPs are implicit, latent, and unstated (as cited in Shohamy, 2006). Thus, it is very important not to take the overt language policies at face value, but to dig inside to examine "what actually happens down on the ground, in the field, at the grass-roots level" (Ibid, p. 51). Thus, language policy has the power in determining the languages and their uses in education and society; therefore, the understanding of the language policy can be achieved through observing the impact of these very devices that are often subtle and hidden from the public eye but have power to determine de facto practices (Ibid). 


\subsubsection{EMI in the UAE}

Using English as a medium of instruction in postcolonial countries has been interpreted from different ideological perspectives (Badry, 2012). One of these widespread frameworks is what Pennycook calls, 'celebratory postcolonial ideology' that explains the adoption of English on the basis of functional and pragmatic considerations by policymakers. From this perspective, embracing English in the educational system is justified by expediency criteria; that implementing English saves huge efforts and time that would be otherwise required if a national language were to be used because for a national language to serve the needs of globalization and the knowledge society of the $21^{\text {st }}$ century, it would need to undergo standardization reforms and corpus planning which might not be easily achievable and may lead to social tensions. Another justification is that not choosing English as MI runs the risk of cutting off future citizens in the periphery from the international and research communities and increasing the barriers of access and participation in the production of knowledge in this global age (Badry, 2012).

\subsubsection{Discrepancy between Language Policies at Pre-Tertiary and Tertiary Levels}

In the UAE, the situation is made complex because it is not clear whether language policy is a top-down or a bottom-up one (Troudi \& AlHafidh, 2017). While language policy at schools seemed until recently to be motivated by national agendas, higher education seems to be motivated by global and pragmatic ones. In public schools in the UAE, Arabic is the medium of instruction while English is taught as a foreign language (Gitsaki, Robby, \& Bourini, 2014). Studying in AMI schools and then moving to EMI universities is one of the hurdles that students face. Shohamy argues that violating human rights has two forms: When students are forced to learn in the prestigious language without recognizing their previous knowledge or their home languages which results in loss of academic knowledge, and when these rights are given and then taken away as it is the case in the UAE when students are granted the right to learn via Arabic language but then this right is taken away at the university level when they have to learn through the medium of English. Shohamy (2006) says, "Not all rights can be viewed positive" (p. 89). She explains that when home language is used as a medium of instruction in schools and not in higher education, and then the language of education at tertiary level is the dominant language, "in such cases when rights are granted at a certain point but taken away at another point" (2006, p. 89), it is severe human rights violation. Sayahi (2015) argues that the impact of the change in the language of instruction is so sharp that it is very similar to immigrating from one educational system to another one in a different county. In their study, Leung and $\mathrm{Lu}$ (2018) pointed out that the students who studied in Chinese medium instruction secondary schools faced more difficulty adjusting to the EMI environment at university level, which made them wish they studied in English at schools.

\subsubsection{First Language Attrition}

For a long time, the knowledge and acquisition of the first language have been thought to occupy a privileged status in the human brain (Schmid \& Kopke, 2007). This faulty assumption has delayed the research in first language attrition, which is relatively new. Researchers have started raising questions about "the possibility that a native language, acquired in infancy, be forgotten or even lost, and if so, under what circumstances and to what extent?" (Ibid). Cook suggests:

As well as the first language influencing the second, the second language influences the first. Perhaps this effect is less detectable in our everyday experience.... It becomes blatant only when the first language starts to disappear, for instance when a speaker brings more and more L2 words into his or her first language (Cook, 2003, p. 1).

Attrition develops in both; bilingual individuals and bilingual societies, whether they are in indigenous or immigrant communities (Negrisanu, 2008, p. 13), and is characterized by "gradual loss of competence in a given language" (Yagmur, 2004, p. 136, as cited in Ibid). Cook (2003) suggests that "as a person gains the ability to use a second language, so he or she may to some extent lose the ability to use the first language. In circumstances where one language becomes less and less used, people do lose their command of it" (p. 12). Moreover, De Bot and Hulsen (2002) suggest that "[n]either first languages nor second languages are immune to loss. With non-use they fade, and though they keep their place in our memory system, they become less accessible up to the point where the knowledge has sunk beyond reach and is for practical purposes lost" (p. 253). Even though attrition can affect the full range of the attritor's linguistic competence and performance, the lexicon is the most "'vulnerable' or 'sensitive' part of the linguistic system, where attrition manifests itself first and most extremely" (Schmid \& Kopke, 2009, p. 211).

L1 attrition is a very complex phenomenon that even after many years of diligent investigation in L1 attrition, theoretical and methodological questions still by far outweigh the answers (Kopke \& Schmid, 2004). Jimenez 
(2007) argues that "despite the numerous efforts dedicated to the study of language attrition in the last two decades, language attrition remains one of the most enigmatic areas in the field of linguistics" (p. 242). In fact, "L1 attrition is a highly complex process that ... depends essentially on the particular circumstances of each speech community" (Ben-Rafael, 2004, p. 166). In recent decades, L1 attrition has been considered one of the typical processes of change that occur among languages in situations of contact. However, researchers do not regard all $\mathrm{L} 1$ changes as indications of attrition.

\subsection{Research Design}

Exploratory critical methodology forms the paradigmatic stance of this study that aims to explore the perceptions of the Arab students regarding their proficiency in academic Arabic in the light of studying in EMI universities, and to critically analyze this political decision on Arabic language. This study is critical in nature that views society and social reality as shaped by the hegemony of power and marked by inequality and therefore aims to help establish equity and to "alleviate pain in society and redress forms of alienation, discrimination, injustice, exploitation, and marginalization" (Troudi, 2015).

\subsubsection{Paradigmatic Position}

The study was approached from interpretive and critical paradigms. Before problematizing or questioning the use of EMI, the study aims to understand how students see this use and how they evaluate their proficiency in Arabic as a result of studying via English. The study is also informed by the critical paradigm because I believe that using English as a medium of instruction is a highly political decision that expresses an unequal power relation between English, the preferred language in academia, and Arabic, the marginalized language.

\subsubsection{Mixed Methods}

A mixed methods research design, a procedure that combines the use of quantitative and qualitative methods, provides a better understanding of the research questions and research problems than using either method by itself (Creswell, 2012). Miles and Huberman state that "at bottom, we have to face the fact that numbers and words are both needed if we are to understand the world" and to convince the readers from different schools of thought (p. 40). Jick (1983) argued that "qualitative and quantitative methods should be viewed as complementary rather than as rival camps" (as cited in Flick, 2007, p. 92).

\subsubsection{Questionnaires}

268 questionnaires were completed by undergraduate Arab students who are now in their third, fourth or fifth year of study in English. Prior to joining the EMI universities, they studied in AMI schools. Almost 500 questionnaires were distributed in the three universities; 200 in the first university, 200 in the second university and 100 in the third university. Because I had to exclude the students who were in international schools, who were in their first and second year, or who studied their high school outside the UAE, I ended up with 268 questionnaires completed by 137 females and 131 male students from different Arab nationalities in the three universities (133 students in the first university, 76 students in the second university, and 59 students in the third university.) The first university had a higher percentage of Arab students who were in Arabic schools than the second one due to different factors such as tuition fees, less IELTS score for joining the university and many other factors that attract Arab students in general and Arab students who were in Arabic schools in specific. That explains the reason behind distributing the same number of questionnaires but excluding more in the second university where most of the students come from International schools. The third university is smaller and had a fewer number of students than the first two universities. The questionnaire participants were studying in different majors; engineering, medicine, business, media, pharmacy, biotechnology, and Law.

\subsubsection{Semi-Structured Interviews}

According to Patton (2002), qualitative data consist of interviews in which "direct quotations from people about their experiences, opinions, feelings and knowledge" are obtained; observations that record "detailed descriptions of people's activities, behaviors, actions" and documents in which "excerpts, quotations, or entire passages" are extracted (as cited in Merriam, 2009, p. 85, Italics added). The interview is the most prominent tool for data collection in qualitative research. Interviews provide "descriptions of the lived world of the interviewees" which can "give voice to common people, allowing them to freely present their life situations in their own words" (Kvale, 2006, p. 481). They also constitute a great chance to explore in conversation and through the participants' stories and anecdotes their attitudes, identities, and ideologies and to gather reports of their language use in different domains (Spolsky, 2000, p. 162). Kvale (2006) describes qualitative research interviewing as "the most sensitive and powerful method for investigating subjects' private and public lives and has often been regarded as a democratic emancipating form of social research" (p. 480). Students who went to 
Arabic medium schools, who spent three and more years in the university were interviewed. The impact of the use of English as MI on students' competence in Arabic would be clearer after students spend three or four years studying in English. The semi-structured interviews aimed to explore their perceptions of their proficiency in Arabic after studying in an EMI university and what changes, if any, occurred to their competence in academic Arabic; and whether they believe the use of English as medium of instruction has affected their language abilities in their first language and whether it has colored their identities and impacted them. The interview also aimed to see how the transition from Arabic schools to EMI university was at social, educational and emotional levels. The interview questions were developed to answer the research questions and to meet the critical agenda of the research (See appendix B). The use of open-ended questions with probing allowed the participants to respond in their own words without forcing them to choose from fixed responses. Their responses would be rich and explanatory, meaningful and unanticipated by the researcher (Cohen et al., 2007). The questions are general and broad to allow the participants to share their views freely unconstrained by the interviewer's perspective (Creswell, 2012).

\subsubsection{Purposive Sampling}

In purposive sampling, which is often considered a feature of qualitative research, the cases to be included in the sample are chosen on the basis of their typicality or the possession of particular characteristics, who are in a position to give in-depth information (Cohen et al., 2007). One objective of qualitative research is to present the complexity of the site or the context of the study and to provide an in-depth account of individuals which means that larger number of cases can become unwieldy and might result in superficial perspectives (Creswell, 2012). Thus, it is typical for a qualitative study to study a few individuals or a few cases (Ibid). In this study, nonprobability purposive sampling was used. Patton (2002) argues that "the logic and power of purposeful sampling lies in selecting information-rich cases for study in depth... [;] those from which one can learn a great deal about issues of central importance to the purpose of the inquiry, thus the term purposeful sampling" (p. 230, emphasis in original). 20 students were interviewed; 12 female students and 8 male students. All the students were Arabs from different nationalities; Egypt, Syria, Algeria, Jordan, Sudan, Palestine, Iraq and Saudi Arabia. They were all in their third, fourth or fifth year of their studies at the university. They are from different majors: chemical engineering, electrical engineering, industrial engineering, nuclear engineering, biotechnology, nutrition, business, pharmacy and media. Three students chose to be interviewed in English while 17 interviews were done in Arabic with a lot of codeswitching from Arabic to English at some points. So, the interviews that were done in Arabic were transcribed in English immediately and sent back to the participants to make sure that the translation was sincerely reflecting what they were saying in Arabic.

\subsubsection{Qualitative Data Analysis}

Qualitative data analysis is an eclectic process that is based on the researcher's trial to make sense of the data, which makes the approaches to qualitative data analysis vary considerably (Creswell, 2012). The process of analyzing the data was very iterative. Even though it went through stages, I kept going back and forth between the phases. In doing the analysis, I followed thematic analysis described by Braun and Clarke with its eight phases. After I transcribed the audiotapes from the interviews, I read them several times to familiarize myself with the data and to obtain a general sense of them. During these readings, I took some notes on the margins of the similar questions and interesting quotes that I thought would form the core of the themes.

\subsubsection{Quantitative Data Analysis}

To prepare the survey data for statistical analysis, I coded all the questionnaires from 1-286. For part 1, I converted the data into numerical form. Then, all data for the three parts were entered into excel sheet. For the quantitative data analysis, I used Excel Sheet where I inserted all the data of the 268 surveys to prepare them for statistical analysis. I coded all the questionnaires from 1-268 and converted the data into numerical form for all the statements of the survey. Frequency and percentages of agreement and disagreement were calculated for each item. Descriptive statistics was used to compute the data for easier reporting. The quantitative data analysis was guided by the research questions (Punch, 2009, p. 261).

\subsubsection{Ethical Considerations}

Ethical transparency and commitment should be observed throughout all the stages of research. Ethics are so important that they "should, without doubt, be at the heart of research from the early design stages right through to reporting and beyond" (Weber et al., 2014, p. 78). Following Bryman's framework (2012) of what ethical research should involve, I obtained the consent of participants, assured them that their participation is voluntary and free from pressure, respected the anonymity and confidentiality of the participants and didn't make unreasonable demands on the participants, with the assurance that participating in the study would not yield any 
harm for them (as cited in Weber et al., 2014). Prior to conducting this research, I obtained the permission from the University of Exeter to do the research.

\section{Results}

\subsection{Students' Perceptions of Their Competence in Arabic Back at School}

The majority of the interviewed students believe that their proficiency in Arabic at school was excellent. They are satisfied with their Arabic back then and attribute that to teaching Arabic as a subject besides taking all subjects in Arabic. They feel that their whole academic life was colored in Arabic.

\subsubsection{Academic Arabic at school- "My Arabic in school was reaaally really good"}

The findings reveal that $64 \%(n=171)$ of the questionnaire participants $(n=268)$ believe that their Arabic at school was excellent, while $26 \%(n=71)$ said it was good, in contrast to only $9.7 \%(n=26)$ who said it was average. This shows that almost all the students were satisfied with their Arabic at school, ranking it as 'excellent' or 'good.' Similarly, almost all the interviewed students were satisfied with their Arabic at school, ranking it as 'excellent' or 'good.' Similarly, all the interviewed students, except for one, said that their Arabic at school was excellent. They described their Arabic proficiency at school as "excellent," "very strong," and "very developed." Marah said, "I was so distinguished in the school in Arabic," while Hadeel said, "My academic Arabic was excellent. Reading and writing were excellent." Lara also pointed out, "My Arabic in school was reaaally really good." The interviewed students were satisfied with the atmosphere of the school that nurtured their love for Arabic. Ayat said, "Back in school I used to read novels in Arabic. We used to exchange novels in class. All our class used to love reading in Arabic. I used to read a novel every week. Nobody used to read in English." Marah said,

I was so distinguished in the school. Since grade four, we had 'ukaz souk' (a traditional Arabic souk that was famous for reciting poetry and literary work) which was for older students to go and listen to poetry. The first time I heard the poem, "record I am an Arab" was there. So, I fell in love with Arabic poetry, literature and language.

\subsection{Academic Arabic After Studying in EMI University}

\subsubsection{Students' Recognition of Their Declining Abilities in Arabic- "Ya Allah I Am Losing My Arabic"}

In response to the question of whether they believe academic Arabic is absent from their university life, 53.6\% $(\mathrm{n}=144)$ agreed and strongly agreed that it is absent from their lives. Only $21.2 \%(\mathrm{n}=57)$ disagreed or strongly disagreed with the statement, while $25.3 \%(n=68)$ were neutral. These findings show very clearly that using English as MI has drawn students away from Arabic and has sidelined Arabic in academia. This absence of Academic Arabic from their lives has led to another issue that is raised by the findings that suggested that almost a third of the surveyed students $(39 \%, \mathrm{n}=105)$ stated that their proficiency in Arabic after studying in the university declined, while almost half of them $(49 \%, \mathrm{n}=132)$ stated that it has been almost the same, and $11.5 \%$ $(\mathrm{n}=31)$ believed that their proficiency in Arabic has improved. When we talk about almost one third of native speakers of the language feeling that their proficiency in their native academic language declined, the percentage becomes significant. Third of the surveyed students are aware of their declining abilities while those who believed it was the same (49\%) might not be aware of their declining abilities in Arabic and believed so because they thought Arabic is their first language and would always be there. Literature suggests that people usually believe that their first language is immune to loss and is so sacred that it will never be wiped out even with disuse (Schimdt, 2010). Also, what the interviews later on revealed and clearly showed is that students who said that their language has been almost the same were not aware of their lost abilities in Academic Arabic until they were interviewed and were asked to talk or write about their majors in Arabic. Only then, they felt that their Arabic, which they thought was fine, was not really good. Samia is one of these students who said that she didn't realize that her Arabic was fading until now. She said, "I did not feel it maybe until now. I didn't feel that it was fading until recently. I knew that I knew words in English that I didn't know in Arabic, but I thought it is momentarily; just in that moment I am not getting the word." Similarly, Aziza didn't realize before the interview her inability to describe her major in Arabic. She discovered that when she was asked in the interview and said, "While talking to you right now, I feel I am dead, destroyed." Also, these students who believed their Arabic has been almost the same might have not taken elective courses in Arabic, like Samia, who suggested that she cannot assess this loss because she is not using the language because she took all electives in English. She says, "I cannot assess my Arabic now because I don't have instances when I have to use it that much. I did not encounter any incidents when I had to use Academic Arabic."

In the interviews, almost all students stated that their Arabic declined. After studying in EMI university for three, 
four or five years, 19 of the 20 interviewed students believe that their Arabic competence has declined even though this decline differed from one interviewee to another. Marah, who is year three in chemical engineering says, "At many times, I feel like writing diaries, but I feel I have now weakness in Arabic, so I stop. But my English vocabulary are entering ... 'Ya Allah' I am losing my Arabic." Hadeel compares her Arabic at first semester and in her last semester at university. She says, "I took Arabic heritage in the first semester while I took the language of the Quran in year four." She realized the huge difference in her competence in Arabic in the two courses. She starts with the course she took in the first semester saying, "When I took Arabic heritage in my first semester, I felt happy, it was the easiest course; very easily memorized; the professor considered me the best in class. I got full marks on all assessments." This changed when she took another course in Arabic in her last semester in the university and made her realize that she lost her abilities in Arabic. She said:

Then, when I took 'the language of the Quran' in the fourth year, I was shocked. When I wanted to answer the questions, and to put down the idea I have in mind on paper, I was not able to, unable to order it quickly in a sentence even though I had the idea in mind. I was used to writing quickly. Sometimes, I would write the sentence and then look at it and say, 'what is this that I am writing?' I felt I was writing like those who never read Arabic in their whole lives. I don't know why.

Thaer also feels that he is forgetting how to read in Arabic. He said, "After studying in English for five years, I feel that I am in a way forgetting how to read MSA perfectly or fast. When I read in MSA, I am kind of slow in the beginning, then I get faster." He added that he noticed his declining Arabic with his increased codeswitching to English. He said, "Every now and then, I notice that my Arabic is getting weaker, not stronger, especially when I use English words in the middle of my sentence or to finish my sentences or when I am confused about how to spell something." Lara also believes that her Arabic declined. She said, "My Arabic got weakened. It really got weakened. I see it every day because I now think in English and speak in Arabic. I sometimes laugh at myself, "what is the hell?'[laughing]."

What students have revealed in the interviews and reported in the questionnaires reveals that students' competence in Arabic has changed after studying in the EMI university. Studying in English made students' brains programmed in English, as some of them suggested, which made speaking about their majors in Arabic very hard for them. The ultimate exposure to sciences in English and being immersed and exposed to their studies only in English made it the language they are comfortable in. A distinction needs to be made here between Arabic as a language of social communication and media that is not in danger and academic Arabic that is affected by the 'English as a language of instruction' policy that "will expedite its erosion as a channel for academic and scientific content" (Troudi, \& Al Hafidh, 2017, p. 106). While students will continue using the colloquial Arabic for communication, it seems that their academic Arabic might deteriorate due to the use of English as a language of instruction. "Certainly, people will continue to speak Arabic, but fluent classical or Modern Standard Arabic (MSA) will become a language of the past" (Al-Issa, 2012, p. 9). Even though half of the surveyed students seemed unaware of that decline, it does not mean it is not there. It might be attributed to their belief that it is their first language and that the disconnect with their Academic Arabic may not affect it. Or, it might be just that they simply do not care about their competence in Arabic because for them now, it does not serve any role and does not have any 'symbolic power in the linguistic market' (Bourdieu, as cited in Bull, 2013). It is not perceived by students as a 'linguistic capital.'

\subsection{Symptoms of Academic Arabic Attrition}

19 out of the 20 interviewed students expressed their inability to talk about their major in Arabic and that if they do, it will be with difficulty, and suffering and it will require longer time. It is very important to keep in mind that "language attrition is a complex and dynamic process of change, development and cross-linguistic interaction" (Schmid, Kopke, \& de bot, 2012, p. 680). However, the attempt here is to see how the decline in the proficiency in academic Arabic is seen by the Arab students who believed that they were experiencing language attrition due to their declining abilities. de Leeuw, Opitz, and Lubin'ska (2013) argue that "lowered proficiency in the L1, or linguistic behavior that differs from 'typical speakers' of the L1, are generally considered to be symptomatic of L1 attrition" (p. 668). Another thing is that for the participants, Arabic is only a native academic language and not purely a native language. This distinction is important.

\subsubsection{Difficulty Recalling Arabic vocabulary - "I Know This Word but Can't Remember it"}

In the questionnaire, in response to the question of whether students find difficulty recalling Arabic words in writing or speaking, $51.8(\mathrm{n}=139)$ said that they never find difficulty recalling Arabic words in speaking or writing, while $48 \%$ ( $n=129)$ said that they 'always' or 'sometimes' find difficulty recalling Arabic vocabulary, which means that almost half of the surveyed students in the three universities cannot retrieve Arabic words from 
memory instantly all the time or at sometimes. 10.4\% said that they always had difficulty recalling Arabic words, and $37.6 \%$ 'sometimes' find difficulty recalling Arabic words in speaking or writing. Interviewed students showed that recalling vocabulary they used to know before was not easy. Imad said, "I used to know many terms that now I cannot remember." Hadeel also felt that she forgot words she used to know before. She says:

Sometimes, the doctor [of the language of Quran] would ask about a meaning of a word that I used to know, and I previously encountered more than once but was unable to recall it anymore. I would sometimes sit in class reading and trying to remember, 'Ya Allah [Oh God], I know this word but can't remember it.' The idea is in my head. I got confused.

Lara says, "I find difficulty expressing what was very easily expressed back then in Arabic, I find it hard to express it now." Lara says the reason is the lack of enough exposure to Arabic. She said:

Before, we were exposed to good Arabic all the time in school. Everything was in Arabic. I was exposed every day to around three hundred words in Arabic, minimum. Now, I am exposed to thirty, way less. This exposure affects me on a daily basis. In terms of writing, competency is still there but it is performance that is affected.

Lara said that she saw that when she tried to present in Arabic what she presented in English, saying: "I had to think twice before saying any sentence because I kind of how to say this in Arabic? It is hard. You know, 'objectives, and goals.... Insights' ... These terms are hard now." The declining abilities in Arabic which is mostly shown in forgetting vocabulary previously learnt is reported in literature. Previous research studies have mentioned that "lexical-semantic knowledge is the most vulnerable part of the linguistic repertoire, deteriorating first, fastest and more dramatically as compared to ... grammar or phonetics" (Schmid \& Jarvis, 2014, p. 729). These difficulties are mostly reported in contact situations, where borrowings and transfer from L2 result in "lexical retrieval difficulties and diminished verbal fluency" (Schmidt, 2007, p. 136). The ability to retrieve an item from memory is determined by the frequency and recency with which it has been previously called upon (Paradis, 2007). Therefore, "less frequent items and items that have not been used for a long time become harder to access" (as cited in Schmid \& Jarvis, 2014, p. 730). Thus, attrition predominantly affects the less frequent lexical items and the speakers who do not use their L1 on a regular basis (Ibid). Using English in the academic context inhibits Arabic words because the attritional process is dependent on "the presence, use and development of the environmental language" because bilinguals tend to inhibit the language they don't activate which may lead to word-finding difficulties (Schmid \& Jarvis, 2014, p. 730). Thus, it is very important to take into consideration not only how much each language is used, but also the contexts of using that language, which affects the degree to which the other language is inhibited in these situations (Schmid, 2007). Because of studying in English, students stopped using the words and expressions they previously used in their twelve years of studying via Arabic and they used English vocabulary instead. This has mostly resulted in forgetting the academic Arabic words and in facing difficulty retrieving them from memory.

\section{Discussion}

\subsection{Marginalization of Arabic and English}

While the Arabic schools teach via Arabic and marginalize English, universities marginalize Arabic and use English as a language of instruction. Both policies need to be revisited and need to be in harmony because they seem to be at war with each other. Both languages are needed for success, either at school or at university level. However, what the two language policies are doing is misleading students. Students upon leaving school felt shocked because they felt that English was insignificant subject at school but is now everything at university while Arabic was everything at school but is now completely marginalized at university. These conflicting messages have resulted in frustration, suffering, academic language attrition and academic challenges for students. Language policies should be enacted in harmony, not in conflict. Students should not be the victims for the discrepancies, differences and conflicts in the language policies. Also, the shift in the language of instruction is violating linguistic human rights. As Shohamy (2006) said, when linguistic rights are granted at one point but taken away at another, in such cases it is severe human rights violation. The participants were granted linguistic rights at school that were then denied at university which made their academic life harder than if they were deprived of that right at school too. This shift would result in discrimination and inequality between "those for whom proficiency in English opens doors and those for whom lack of proficiency in English closes doors" (Piller \& Cho, 2013, p. 29). The Arab students who come from Arabic schools "are forced to bear the burden of underperformance by being relegated to a progressively shrinking sphere of opportunity" (Ibid, p. 31) academically and socially. Therefore, a very important question will be: To what extent does "the language of instruction, contribute to perpetuating discrimination and underachievement among certain groups of students?" 
(Cummins, 2000, p. 34).

\subsection{EMI and Academic Language Attrition}

This shift in the language of instruction has resulted in academic language attrition of Arabic. The participants felt that their proficiency in Arabic declined due to lacking the chances of using EMI and being exposed to English only. The knowledge they previously gained at school is threatened due to the EMI policy. In a similar context, Hill (2016) in his study of the transition from Ma-ori-medium education to English concluded that "leaving Ma-ori-medium education behind meant the students ... were cut off from a significant language maintenance context" (p. 50). Therefore, if academic Arabic language is abandoned and not developed further, students' abilities in it are expected to decline, especially if we consider the diglossic nature of Arabic and the restrictions of using academic Arabic. It is very important that "the first language should not be abandoned before it is fully developed" (Hornberger, 2003, p. 23). Thus, if a mother tongue is not used in academic writing, research, and university teaching, it will definitely stagnate and then decline. This is in line with what Brock-Utne found out when she encountered some of her Tanzanian colleagues who were unable at a certain point in the academic conversation to continue in their mother tongue and their English words increased or would switch completely to English because "the vocabulary they need has not been allowed to develop at the highest academic level" (p. 226) as a result of EMI at university level, as it is the case with the participants of this study who reached a level in the interview where they were completely unable to talk about their majors or courses in Arabic because their academic Arabic vocabulary were not developed. Schmid and Kopke (2009) argue that the process that we refer to as L1 attrition is due to two factors: "the presence, development and (eventually) dominance of the L2 system", which is probably what all bilinguals experience, while the second and the more important factor is "the dramatic reduction in L1 use and input" which leads to a structural reduction and simplification in the language system" (p. 211).

\section{References}

Ahmed, K. (2011). Casting Arabic culture as the 'other': Cultural issues in the English curriculum. In C. Gitsaki (Ed.), Teaching and learning in the Arab World (pp. 119-137). Peter Lang: Bern, Switzerland.

Airey, J. (2009). Science, language and literacy: Case studies of learning in Swedish University physics. Unpublished thesis: Uppsala University.

Badry, F. (2012). Education in the UAE: Local identity and global developments. Essentials of School Education in the United Arab Emirates (pp. 85-108). The Emirates Center for Strategic Studies and Research.

Baker, C. (2011). Foundations of Bilingual Education and Bilingualism. Bristol: Multilingual Matters.

Ben-Rafael, M. (2004). Language contact and attrition: The spoken French of Israeli Francophones. In M. S. Schmid, B. Kopke, M. Keijzer, \& L. Weilemar (Eds.), First language attrition: Interdisciplinary perspectives on methodological issues. Amsterdam: John Benjamins Publishing Company. https://doi.org/10.1075/sibil.28.10ben

Brock-Utne, B. (2001). The growth of English for academic communication in the Nordic countries. International Review of Education, 47(3/4), 221-233. https://doi.org/10.1023/A:1017941523866

Brock-Utne, B. (2007). Learning through a familiar language versus learning through a foreign language-a look into some secondary school classrooms in Tanzania. International Journal of Educational Development, 27(5), 487-498. https://doi.org/10.1016/j.ijedudev.2006.10.004

Bull, T. (2013). Linguistic emancipation and the linguistic market place. SOLS, 7(1), 33-55. https://doi.org/10.1558/sols.v7i1-2.33

Chapple, J. (2015). Teaching in English is not necessarily the teaching of English. International Education Studies, 8(3), 1-13. https://doi.org/10.5539/ies.v8n3p1

Cohen, L., Manion, L., \& Morrison, K. (2007). Research Methods in Education (6th ed.) London: Routledge Falmer. https://doi.org/10.4324/9780203029053

Coleman, J. A. (2006). English-medium teaching in European higher education. Language teaching, 39(1), 1-14. https://doi.org/10.1017/S0261444800012659

Cook, V. (2003). Introduction: The changing L1 in the L2 user's mind. In V. Cook (Ed.), Effects of the first language on the first (pp. 1-18). Multilingual Matters LTD: Clevedon.

Creswell, J. W. (2012). Educational Research: Planning, conducting, and evaluating quantitative and qualitative research (4th ed). Pearson: Boston. 
Cummins, J. (2000). Language, power, and pedagogy: Bilingual children in the crossfire. Clevendon: Multilingual Matters Limited. https://doi.org/10.21832/9781853596773

de Leeuw, E., Opitz, C., \& Lubin'ska, D. (2013). Dynamics of first language attrition across the lifespan. International Journal of Bilingualism, 17(6), 667-674. https://doi.org/10.1177/1367006912454618

Ennser-Kananen, J., Escobar, C. F., \& Bigelow, M. (2017). "It's practically a must": Neoliberal reasons for foreign language learning. International Journal of Society, Culture and Language, 5(1), 15-28.

Gitsaki, C., Robby, M. A., \& Bourini, A. (2014). Preparing Emirati students to meet the English language requirements for higher education: A pilot study. Education, Business and Society: Contemporary Middle Eastern Issues, 7(2/3), 167-184. https://doi.org/10.1108/EBS-10-2013-0037

Grant, N. (2009). Foreword. In D. Hill \& R. Kumar (Eds.), Global neoliberalism and education and its consequences (pp. vii-xvii). New York: Routledge.

Hill, R. (2016). Transitioning from Māori- medium to English: Pursuing biliteracy. Educ Stud, 51, 33-52.

Ha, P, L., \& Barnawi, O. Z. (2015). Where English, neoliberalism, desire and internationalization are alive and kicking: Higher education in Saudi Arabia today. Language and Education, 29(6), 545-565. https://doi.org/10.1080/09500782.2015.1059436

Hornberger, N. H. (2002). Multilingual language policies and the continua of biliteracy: An ecological approach. Language Policy, 1, 27-51. https://doi.org/10.1023/A:1014548611951

Jimenez, A. J. (2004). A sociocultural approach to language attrition. In M. S. Schmid, B. Kopke, M. Keijzer, \& L. Weilemar (Eds.), First language attrition. Interdisciplinary perspectives on methodological issues. Philadelphia: John Benjamins Publishing Company: Philadelphia. https://doi.org/10.1075/sibil.28.05jim

Kvale, S. (2006). Dominance through interviews and dialogues. Qualitative Inquiry, 12, 480-500. https://doi.org/10.1177/1077800406286235

Marsh, D. (2006). English as medium of instruction in the new global linguistic order: Global characteristics, local consequences. METSMaC.

Masri, T. I. (2018). The professional identity of adjunct faculty: Exploratory study at a private university in the UAE. English Language Teaching, 11(10), 16-29. https://doi.org/10.5539/elt.v11n10p16

Masri, T. I. (2015). University students in the writing courses from the centre to the periphery: A critical perspective. International Journal of Bilingual \& Multilingual Teachers of English, 2(3), 117-129. https://doi.org/10.12785/ijbmte/030206

McKay, S. L. (2010). English as an international language. In N. H. Hornberger, \& S. L. McKay (Eds.), Sociolinguistics and language education (pp. 89-115). Bristol: Multilingual Matters. https://doi.org/10. 21832/9781847692849-006

Merriam, S. B. (2009). Qualitative research: A guide to design and implementation. John Wiley \& Sons, Inc. San Francisco: USA.

Negrisanu, R. M. (2008). Aspects of first language attrition: A case study of German immigrants in East Tennessee. $\mathrm{PhD}$ dissertation, University of Tennessee.

Pennycook, A. (2001). Critical applied linguistics: A critical introduction. Mahwah, NJ: Lawrence Erlbaum.

Pennycook, A. (2006). Postmodernism in language policy. In T. Ricento (Ed.), An introduction to language policy: Theory and method (pp. 61-76). Oxford: Blackwell Publishing.

Piller, I., \& Cho, J. (2013). Neoliberalism as language policy. Language in Society, 42, 23-44. https://doi.org/10.1017/S0047404512000887

Sayahi, L. (2015). A moving target: Literacy development in situations of diglossia and bilingualism. Arab Journal of Applied Linguistics, 1(1), 1-18.

Schmid, M., \& Kopke, B. (2009). L1 attrition and the mental lexicon. In A. Pavlenko (Ed.), The bilingual mental lexicon: Interdisciplinary approaches (pp. 209-238). Multilingual Matters: UK. https://doi.org/10.21832/ 9781847691262-011

Schmid, M., \& Jarvis, S. (2014). Lexical access and lexical diversity in first language attrition. Bilingualism: Language and Cognition, 17(4), 729-748. https://doi.org/10.1017/S1366728913000771

Schmid, M. S., Kopke, B., de bot, K. (2012). Language attrition as a complex, non-linear development. 
International Journal of Bilingualism, 17(6), 675-682. https://doi.org/10.1177/1367006912454619

Shohamy, E. G. (2006). Language policy: Hidden agendas and new approaches. Routledge: New York. https://doi.org/10.4324/9780203387962

Spolsky, B., \& Shohamy, E. (2000). Language practice, language ideology, and language policy. In R. D. Lambert., \& E. Shohamy (Eds.), Language policy and pedagogy: Essays in honor of A. Ronald Walton (pp. 1-41). John Benjamins Publishing Company: Philadelphia: USA. https://doi.org/10.1075/z.96.02spo

Troudi, S., \& AlHafidh, G. (2017). The Dilemma of English and its roles in the United Arab Emirates and the Gulf. In A. Mahboob, \& T. Elyas (Eds.), Challenges to Education in the GCC during the 21st Century (pp. 93-116). Cambridge, England: Gulf Research Centre.

Troudi, S. (2015). Becoming a critical researcher in language education and TESOL. In C. Coombe, \& J. B. Dean (Eds.), The Cambridge Guide to Research in Language Learning and Teaching. Cambridge: Cambridge University Press.

Yeung, M., \& Lu, V. (2018). English-medium instruction in self-financing tertiary institutions in Hong Kongviews and practices from the students. English Language Teaching, 8(11), 28-39. https://doi.org/10.5539/ elt.v11n8p28

\section{Copyrights}

Copyright for this article is retained by the author(s), with first publication rights granted to the journal.

This is an open-access article distributed under the terms and conditions of the Creative Commons Attribution license (http://creativecommons.org/licenses/by/4.0/). 